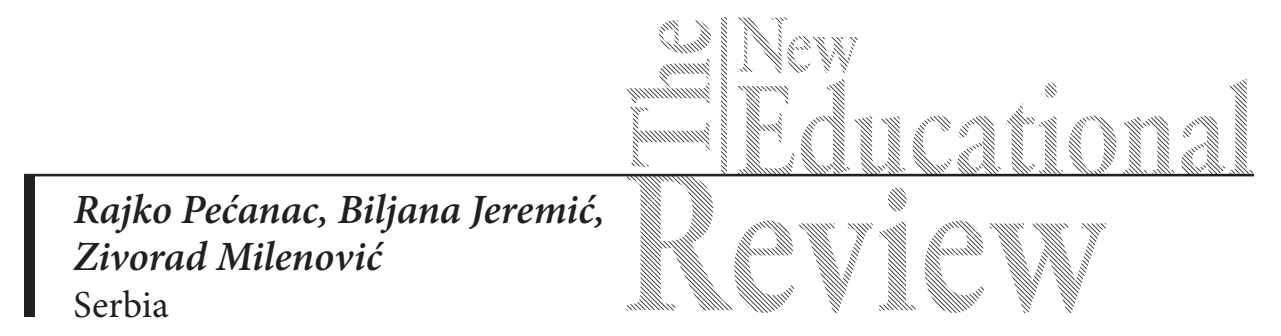

\title{
Digital Media in the Teaching of Music Education
}

DOI: 10.15804/tner.2016.43.1.20

\begin{abstract}
The paper examines the contribution of learning with the help of digital media to the quality of students' knowledge when getting acquainted with the basics of musical literacy in the teaching of Music Education in lower primary school grades (school year 2013/14, a sample of 78 fourth grade students from Serbia $\mathrm{E}=39 ; \mathrm{C}=39$ ). The research results have shown that the students from the experimental group $(\mathrm{M}=4.05 ; \mathrm{SD}=.972)$ achieved better results in musical literacy in the final test by learning with the help of digital media, for this kind of work compared to the students from the control group $(\mathrm{M}=3.15, \mathrm{SD}=$ $1.309)$, who learned in the traditional way: $\mathrm{t}(78)=-3.438$; average difference $=$ $-0.897 ; 95 \% \mathrm{CI}$ : from -1.418 to $-0.377 ; \eta=0.134$.
\end{abstract}

Keywords: educational technology, innovative teaching, musical literacy

\section{Introduction}

In an era of advancing science and technology, digital media have an important place in the teaching process. Modern technology has changed the way and quality of life, but the situation in schools has remained the same. There are very few schools that are equipped with modern teaching aids including digital media, which enhance the very process of learning and teaching. One of the ways to achieve this is through the use of cognitive tools for building knowledge, whereby students are given an opportunity to be creators, through their own interpretation and organization of knowledge (Reeves, 1998). In this paper, the term digital media refers to all types of information in a digital format, including computer-generated text, graphics and animation, as well as photographs, animation, 
sound and video. The mode of communication between students and digital media is simple and straightforward and can be accomplished in various ways (practicing, teaching, dialogue, information search, simulation, educational games, problem solving). The communication model used in teaching is perhaps the most important segment that largely determines the outcome and effectiveness of the process (Pećanac, Lambić \& Marić, 2011: 62). The combination of text, sound, images and animations ensures students' motivation for learning about the basics of musical literacy through the use of digital media. The textual information must be clear and tailored to the student and it must explain the essence of what is taught (Milenović, 2012). It should be accompanied by an appropriate image, photograph or illustration. The image must reflect reality, in order to satisfy the principle of obviousness. Information can also be given in such a way that by reading and watching, the student combines or reorganizes it and comes up with new knowledge by doing so (Tobias, 1989). The presence of computer games with levels for children is particularly stimulating, these games level the playing field when it comes to children with developmental disorders and learning disabilities, i.e. lower-ability students and students with special needs (Hill, Reeves, Grant, Wang, \& Han, 2002).

Digital media have a variety of uses in education: from teaching programs for learning and practicing, from databases and tools, through learning games, experiments and simulations, to complex communication and cooperation environments. The application of digital media in education is in itself neither good nor bad, and the results of such application will depend primarily on how they are applied in learning and teaching. It is noticeable that the question is not whether learning with the help of digital media is feasible, but to consider the most appropriate ways of effective integration into the educational program. This means that music technology, exemplified in computer-based music, music software, digital audio software, the digital piano, music notation software, laptops, personal digital players like Apple's iPod, MIDI keyboard etc., must find its place in the teaching and learning of music education (Webster, 2002). Musical literacy includes the concepts of time - the duration of tones, tempo and musical meter, rhythm, symbols (treble clef, line system) and the dynamics (symbols for volume). The teaching of musical literacy refers to the process in which students are trained to consciously observe and reproduce rhythmic and melodic flows. This actually means consciously recognizing sound and singing and playing from sheet music. It aims to bring students to an understanding of music and its laws through basic means of musical expression - rhythm, melody, harmony, tempo, dynamics and articulation (Jeremić, 2013). 
The new approach to adopting the basics of musical literacy with the help of digital media, presented in this paper, is oriented towards planning, realization and evaluation of student achievements. It is reflected in the innovation of the methodological approach of the traditional education process with an aim to improve and enrich it. The practical contribution of the conducted research is the conception of teaching units, design, production and possibility of use of digital media in the teaching area of gaining musical literacy.

\section{$\underline{\text { Research Methodology }}$}

With regards to the possibilities of the application of digital media, a problem of this research was set out: an insufficient use of the possibilities and application of digital media in the teaching of Music Education, aimed at examining the possibilities of improving the teaching process, a higher quality of intellectual enrichment of students, their higher achievements, conditioned by adequate preparation and application of digital teaching contents in the teaching process. The subject of the research is the study of the possibilities of realization and organization of teaching by introducing modern teaching trends in regular classes, through the implementation of a variety of digital media in the teaching process, presented through modern media means, such as: a desktop computer, laptop, video beam projector, DVD and CD player. Depending on the method of teaching, empirical research was carried out, and through direct educational work and work with the use of digital media, the results of students' knowledge were obtained by applying the final test. The experimental research presented in this paper was conducted in the school year 2013/14, on a sample of 78 fourth grade primary school students from Serbia $(\mathrm{E}=39 ; \mathrm{C}=39)$.

The aim of the research was to determine the influence that the application of digital media has on the students' knowledge in the teaching of Music Education. The tasks of the research were to determine whether teaching Music Education through the use of digital media, in the adoption of the basics of musical literacy, has a positive impact on increasing the level of knowledge acquisition in relation to the realization of teaching following the traditional model, and to examine the experimental group students' evaluations about the application and possibilities of digital media in the teaching process of the subject of Music Education. The research starting point was the general hypothesis that digital media contribute significantly to the efficiency of teaching Music Education in lower primary school grades but that they are insufficiently used by teachers in their work. The special 
hypotheses that the students from the E-group will achieve better results when it comes to the degree of knowledge acquisition through the use of digital media in acquiring the basics of musical literacy in relation to the C-group and that the students from the E-group will have positive evaluations about the application of digital media in the acquisition of musical literacy knowledge, were also starting points of the research.

The basic methodological procedure in this experimental research was based on a model of an experiment with parallel groups ( $\mathrm{E}$ and $\mathrm{C}$ ). In the realization of the project of this research it is possible to distinguish several phases: the prephase, consisting of the development of the experimental program, the first phase - the initial survey involved the testing of subjects (E and C), i.e. the assessment of the level of students' musical literacy by using the Scale for assessing vocal abilities - SPVS (Serb. Skala za procenu vokalnih sposobnosti), subtests I and IV (Jeremić, 2011), a Likert type scale with answers ranging from 1 to 5, modified for the purposes of the research, where degrees are equivalent to the number of points $1=0-5 ; 2=6-8 ; 3=9-10 ; 4=11-13 ; 5=14-16$. The testing was conducted individually with each student respondent, with questions about music that had pre-standardized content. This initial testing was conducted in September 2013. The second phase was the introduction of an experimental factor in the experimental class. The third phase was final testing. The fourth phase consisted in data collection with the help of tests and a survey questionnaire (assessing students' evaluations about the application and possibilities of digital media in the teaching process, i.e. in the education process) given to the respondents from the E group.

The following research methods were used: a descriptive-analytical method, a causal method (experimental method) and a comparative method. Techniques for testing and surveying were used in the research. Among them, as research instruments the tests (initial and final tests) and the survey questionnaire. The goal of testing students in the initial test was to determine the students' level of knowledge in the teaching area which was taught during the previous school year, which allowed for the formation of the experimental and control groups. What was assessed was, therefore, the level of already acquired knowledge. The teaching area in question was the basics of musical literacy, according to the curriculum for the fourth grade of primary school. The goal of the final test was to determine the extent to which the students had acquired the teaching contents that were taught, i.e. the importance of the application of digital media in the teaching process. All tasks included the concepts from the field of music theory according to the curriculum for the fourth grade of primary school- (1) characteristics of the tone (length, height and strength), writing notes in a line system, solmisation names of 
tones, (2) melodic - aligning tones in the C major scale and (3) rhythm - duration of tones (whole, half, quarter and eighth notes).

Teaching with the help of digital media was applied in the realization of contents (1) characteristics of the tone - length, height and strength (processing the teaching unit with the use of educational computer software implemented via the Flash MX 2004 computer program); (2) line system, writing notes in a line system, solmisation names of tones, (processing the teaching unit realized with the use of Sibelius 6.0: Professional music notation software); (3) melodic - aligning tones in the $\mathrm{C}$ major scale (processing of teaching units with the implementation of various aspects of digital media presented through modern media means, presenting PowerPoint slides with the use of graphics, animation and sound sequences) and (4) rhythm - duration of tones, whole, half, quarter note and metrics - types of pulses 2/4,3/4 and 4/4 (processing of the teaching unit with the use of Sibelius 6.0: Professional music notation software). Because of the fact that the students did not have much experience with learning with the help of digital media, as well as the fact that these are students at a younger age (10 years old), they worked in groups of three, with verbal instructions from teachers and a written instruction in the form of an instructional (teaching) pamphlet. The instructional pamphlet comprised steps which helped the students to follow and understand the slides that appeared on the monitor screen. The survey had the purpose of assessing the perceptions of the students from the experimental group about the application and the possibilities of the use of digital media in the teaching process, i.e. in the education process. The survey was conducted upon the completion of the research.

\section{Results}

Testing of differences between the respondents from the control and experimental groups in the initial test was conducted first.

Table 1. Achievement of students from the experimental and the control groups in the initial test

\begin{tabular}{lccccc}
\hline & N & M & SD & $\begin{array}{c}\text { Mean } \\
\text { Rank }\end{array}$ & $\begin{array}{c}\text { Sum } \\
\text { of Ranks }\end{array}$ \\
\hline C-group & 39 & 15.67 & 4.858 & 39.49 & 1540.00 \\
\hline E-group & 39 & 15.64 & 4.858 & 39.51 & 1541.00 \\
\hline
\end{tabular}


The mean score of the respondents from the control group obtained in the initial test is 15.67, with a standard deviation of 4.858. The mean score of the respondents from the experimental group obtained in the initial test is 15.64 , with a standard deviation of 4.859 (Table 1). This indicates that the students studied the content related to the field of musical literacy in the traditional way.

Table 2. Correlation between respondents from the control and the experimental groups

\begin{tabular}{llrc}
\hline & & C-group & E-group \\
\hline Score of the & $\mathrm{r}$ & 1 & .156 \\
\cline { 2 - 4 } C-group & $\mathrm{p}$ & & .344 \\
\cline { 2 - 4 } & $\mathrm{N}$ & 39 & 39 \\
\hline Score of the & $\mathrm{r}$ & .156 & 1 \\
\cline { 2 - 4 } \begin{tabular}{l} 
E-group \\
\cline { 2 - 4 }
\end{tabular} & $\mathrm{p}$ & .344 & 39 \\
\cline { 2 - 4 } & $\mathrm{N}$ & 39 & \\
\hline
\end{tabular}

The correlation coefficient for the control and experimental groups, $r=.156$, did not reach the level of statistical significance $(\mathrm{p}=.344)$, indicating that there is no statistically significant difference between the results on the initial knowledge test between the respondents from the control and the experimental groups (Table 2).

To test the significance of the difference between the rank level data, the Mann Whitney U test was performed.

Table 3. Results of students from the experimental and the control groups in the initial test

\begin{tabular}{lc}
\hline & Achievement in the initial test \\
\hline Mann-Whitney U & 760.000 \\
\hline Wilcox on W & 1540.000 \\
\hline $\mathrm{z}$ & -.005 \\
\hline $\mathrm{p}$ & .996 \\
\hline
\end{tabular}

The Mann-Whitney U test did not reveal a statistical significance regarding the students from the experimental and the control groups in the initial test, so it can be concluded that the experimental and the control groups are equal: $U=760.000$, $\mathrm{z}=-.005, \mathrm{p}=.996$ (Table 3$)$. 
After completing the experiment, testing of differences between the respondents from the control and the experimental groups was conducted in the final test.

Table 4. Achievement of students from the experimental and the control groups in the final test

\begin{tabular}{lcccc}
\hline & $\mathrm{N}$ & $\mathrm{M}$ & $\mathrm{SD}$ & $\Sigma$ \\
\hline C-group & 39 & 3.15 & 1.309 & .210 \\
\hline E-group & 39 & 4.05 & 0972 & .156 \\
\hline
\end{tabular}

The final testing of the students' knowledge was carried out after introducing the experimental program of the subject Music Education for the fourth grade of primary school. The final testing of knowledge was done through a final knowledge test (experimental group, control group). The tasks in the final test included the new teaching content that had been taught. The results of the final test in its entirety, for the control and the experimental groups, are shown in Tables 4, 5 and 6 and in Chart 1. It is possible to note that the respondents from the experimental group obtained significantly better results in the final measure than the control group respondents. The mean score of the respondents from the control group in the final test is 3.15 , with a standard deviation of 1.309 . The mean score of the experimental group in the final test is 4.05 , with a standard deviation of .972 .

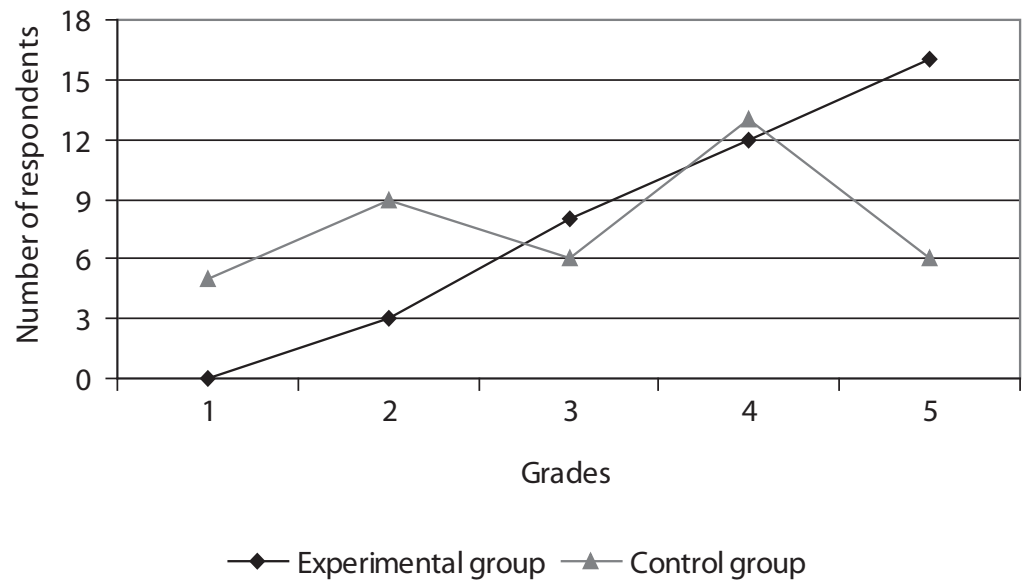

Chart 1. Achievement in the final test 
The link between the achievements of the control and the experimental groups of students in the final test was explored with the use of the Pearson coefficient of linear correlation (Table 5). The estimated value of the magnitude of the correlation coefficient for the achievements of the control and the experimental groups in the final test shows a strong positive value of $r=.904$. The two observed features depend on one another to a very low degree. The high value of their coefficient is derived from some third feature that directly and simultaneously affects both of these features. Given that the value $r=0.904$ is close to 1 , we can conclude that there is a strong positive relationship between these variables. It may be concluded that this relationship is real and not a coincidence, as shown by the value of the reliability test, which is statistically significant $(\mathrm{p}=.000)$.

Table 5. Correlation results for the control and the experimental groups

(Pearson's linear correlation)

\begin{tabular}{llcc}
\hline & & C-group & E-group \\
\hline $\begin{array}{l}\text { Achievement of } \\
\text { the C-group }\end{array}$ & $\mathrm{r}$ & 1 & $.904^{* *}$ \\
\cline { 2 - 4 } & $\mathrm{p}$ & & .000 \\
\cline { 2 - 4 } & $\mathrm{N}$ & 39 & 39 \\
\hline $\begin{array}{l}\text { Achievement of } \\
\text { the E-group }\end{array}$ & $\mathrm{r}$ & $.904^{\star *}$ & 1 \\
\cline { 2 - 4 } & $\mathrm{p}$ & .000 & 39 \\
\cline { 2 - 4 } & $\mathrm{N}$ & 39 & \\
\hline
\end{tabular}

Data show (Table 5) that there is a positive correlation between the achievement of the students from the experimental and the control groups in the final test $(\mathrm{r}=.904)$, which is indicative of a high correlation when using Cohen's criteria.

Table 6. Achievements in the final test by applying t-test

\begin{tabular}{|c|c|c|c|c|c|c|c|c|c|}
\hline & \multicolumn{4}{|c|}{$\begin{array}{l}\text { Levene's Test } \\
\text { for Equality } \\
\text { of Variances }\end{array}$} & \multicolumn{5}{|c|}{ t-test for Equality of Means } \\
\hline & \multirow[t]{2}{*}{$\mathrm{F}$} & \multirow{2}{*}{$\mathrm{p}$} & \multirow[t]{2}{*}{$\mathrm{T}$} & \multirow[t]{2}{*}{ df } & \multirow{2}{*}{$\mathrm{p}$} & \multirow[t]{2}{*}{ M } & \multirow[t]{2}{*}{$\sigma$} & \multicolumn{2}{|c|}{$\begin{array}{l}95 \% \text { Confidence Inter- } \\
\text { val of the Difference }\end{array}$} \\
\hline & & & & & & & & Lower & Upper \\
\hline $\begin{array}{l}\text { Equal vari- } \\
\text { ances assumed }\end{array}$ & 6.779 & .011 & -3.438 & 76 & .001 & -.897 & .261 & -1.417 & -.378 \\
\hline $\begin{array}{l}\text { Equal var- } \\
\text { iances not } \\
\text { assumed }\end{array}$ & & & -3.438 & 70.142 & .001 & -.897 & .261 & -1.418 & -.377 \\
\hline
\end{tabular}


Data show that the students from the experimental group obtained a significantly better result in the final test compared to the students from the control group. According to the results of the t-test, it can be seen that a statistically significant difference was found between the values of the achievement of the students from the E-group $(\mathrm{M}=4.05 ; \mathrm{SD}=.972)$ in the final test compared to the students from the C-group $(\mathrm{M}=3.15$; $\mathrm{SD}=1.309)$ : $\mathrm{t}(70.142)=-3.438$ (Tables 4 and 6). The difference between the mean values per group (mean difference $=-.897,95 \%$ confidence interval extends from -1.418 to -.377) expressed as the indicator eta squared is high $(\eta=.134)$.

Assessing the evaluations of the students from the experimental group was carried out with the use of a questionnaire. The results were obtained by answering openended and multiple choice questions. Honesty in the respondents' responses was achieved by the anonymity of the survey questionnaire. The questionnaire consisted of 8 questions grouped into following categories: (a) an evaluation of classes, in questions 1 and 2; (b) students' interest in this type of teaching, in questions 3, 4 and 5; (c) understanding of the teaching material, 6 and 7; (d) pedagogical implications, question 8 . The aim of the survey was to determine how the students from the experimental group perceived the application of the experimental program, their attitude towards teaching in which digital media are used, their motivation and desire for such a method of work. The survey questionnaire was therefore conducted with the students from the experimental group, i.e. from the group in which an experimental factor had been introduced, and it was conducted immediately upon the completion of the research. Chart 2 shows that the majority of the students are of the opinion that classes realized with the use of digital media were very interesting (75.55\%) and interesting (17.74\%), while $6.71 \%$ of the students considered this method of teaching as usual. The high percentage $(93.29 \%)$ of the students who positively evaluated teaching in which digital media are applied is very encouraging.

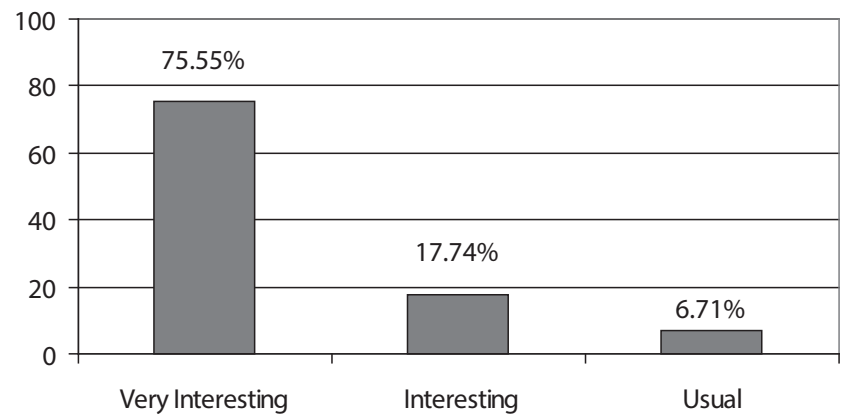

Chart 2. Evaluation of classes in which digital media were used 


\section{Discussion and conclusions}

A high motivation for learning was observed in the students during teaching with the help of digital media. Teaching with the help of digital media develops students' sense of control over a part of the teaching process and, related to this, a sense of safety and satisfaction with what is achieved. In primary school, at a younger school age, reading sheet music is a part of musical literacy, which takes place gradually, starting with images and symbols all the way to written sheet music. An American psychologist, Jean Bamberger (2000), outlines two phases on the basis of studies on the development of early musical literacy with the help of colourful notes (image notation): the figurative phase of graphic representation (symbols next to one another, ranging symbols one next to the other) and the phase of metric representation (where the sounds and duration are expressed in symbols). Teaching with the application of digital media, therefore, appears as an innovative teaching tool, which contributes to the efficiency of teaching Music Education in lower primary school grades (Garcia, Mirra, Morrell, Martinez \& Scorza, 2015; Ranker, 2015). All of this has been confirmed in this research, whose results show that the students who attended classes in which digital media were used had significantly better academic achievements compared to the students who attended traditional classes, which confirms the first specific hypothesis of this research.

The students who had experience in teaching realized by using digital media positively evaluated its significance. For them, digital media have become a means of motivation for independent research in classes (Gleen, 2015). Besides, they also developed an interest in new knowledge in classes, which is not directly related to the teaching contents that are taught (Fawns, 2015).

The obtained research results show that learning with the use of digital media contributed to a greater quality of the students' knowledge in the field of musical literacy in the subject of Music Education than learning in the traditional way, which confirms the main hypothesis. The students from the experimental group obtained better results than the students from the control group in the final test. They managed, in a larger number, to solve the tasks in which they needed to apply the knowledge and perform music by singing and playing by following sheet music. This is also confirmed by different achievements of two primary school students of the fourth grade who are a part of the model of education for all, i.e. inclusive education. Both students with developmental disabilities and barriers to learning and participation, i.e. with special educational needs, attend regular classes, and were included in the research. This research confirmed the importance 
of both digital media and educational technology in working with children with special educational needs. This is also indicated by numerous research studies conducted all over world, in which the importance of educational technology, primarily assistive technology in inclusive classes, was determined (Schwartz, 2015; Nowell, 2014; Oravec, 2012). What we wish to emphasize is the difference in the achievements of the two students in the final test. The student from the experimental group obtained grade three (3), while the student from the control group obtained only one point. It is believed that the experimental method of work performed with the use of digital media greatly assisted the experimental group student in mastering the teaching material.

The analysis of the student survey questionnaire results showed that the surveyed students appreciated the method of work performed with the use of digital media, and that most of them would like to learn in this way more often. The digitalized information can be more easily assembled with the use of images, animation and sound; they simultaneously affect more than one of the senses providing more complete information. Teaching accomplished in this manner can facilitate learning and understanding of teaching contents. Digital media not only contribute to the efficiency of teaching, as confirmed by the results of this research as well, but they also represent a factor of creativity and innovativeness of students in class (Hoban, Nielsen \& Shepherd, 2013). Also, they contribute to the increase in general digital literacy, including music literacy (Park \& Burford, 2013). Regardless of the undoubted importance of digital media, they are insufficiently used in teaching even in countries with developed education systems (Fry, 2015). This confirms the general hypothesis which was the starting point of this research that digital media significantly contribute to the efficiency of teaching Music Education in lower primary school grades, but that teachers do not use them sufficiently in their work.

The results of this research provide a basis for further research which would be oriented towards students as the users of digital media in classes of Music Education, in terms of their need and motivation to use such a form of education, as well as towards teachers as the organizers of the teaching process.

\section{References}

Bamberger, J. (2000). Developing Musical Intuitions. Oxford University.

Fawns, T. (2015). Lessons from Personal Photography: The Digital Disruption of Selectivity and Reflection. Tech Trends: Linking Research and Practice to Improve Learning, 59(1), 50-55. 
Fry, K. (2015). Developing Media Literacy: Managing Fear and Moving Beyond. Journal of Media Literacy Education, 6(3), 65-70.

Hill, J.R., Reeves, T., Grant, M., Wang, S., \& Han, S. (2002). The impact of portable technologies on teaching and learning: Year three report. Retrieved April 8, 2005 from http://lpsl. coe.uga.edu/Projects/aalaptop/pdf/aa3rd/Year3ReportFinalVersion.pdf

Hoban, G., Nielsen, W. \& Shepherd, A. (2013). Explaining and Communicating Science Using Student-Created Blended Media. Teaching Science, 59(1), 32-35.

Garcia, A., Mirra, N., Morrell, E., Martinez, A. \& Scorza, D. (2015). The Council of Youth Research: Critical Literacy and Civic Agency in the Digital Age. Reading \& Writing Quarterly, 31(2), 151-167.

Glenn, C. (2015). Activism or “Slacktivism?": Digital Media and Organizing for Social Change. Communication Teacher, 29(2), 81-85.

Jeremić B. (2011). Darovitost, talenat i kreativnost - odrednice. [Giftedness, Talent and Creativity - guidelines]. Obrazovna tehnologija,12(3), 277-286.

Jeremić B. (2013). Recognition and support program for children talented for music at junior age of school children. Metodički obzori, 8(2), 97-109.

Milenović, Z. (2012). The impact of secular western education on Albanians in primary schools in southern Serbia. International Journal of pedagogies and learning, 7(3), 191-199.

Nowell, S. (2014). Using Disruptive Technologies to Make Digital Connections: Stories of Media Use and Digital Literacy in Secondary Classrooms. Educational Media International, 51(2), 109-123.

Oravec, J. (2012). Digital Image Manipulation and Avatar Configuration: Implications for Inclusive Classrooms. Journal of Research in Special Educational Needs, 12(4), 245-251.

Park, S. \& Burford, S. (2013). A Longitudinal Study on the Uses of Mobile Tablet Devices and Changes in Digital Media Literacy of Young Adults. Educational Media International, 50(4), 266-280.

Pećanac, R., Lambić, D., \& Marić, M. (2011). The Influence of the Use of Educational Software on the Effectiveness of Communication Models in Teaching. The New Educational Review, 26(4), 60-70.

Ranker, J. (2015). The Affordances of Blogs and Digital Video: New Potentials for Exploring Topics and Representing Meaning. Journal of Adolescent \& Adult Literacy, 58(7), 568-578.

Reeves, T. (1998). The impact of media and technology in schools: A research report prepared for the Bertelsmann Foundation. University of Georgia.

Schwartz, L. (2015). A Funds of Knowledge Approach to the Appropriation of New Media in a High School Writing Classroom. Interactive Learning Environments, 23(5), 595-612.

Tobias, S. (1989). Using computers to study consistency of cognitive processing of instruction. Computers in Human Behavior, 5(2), 107-118.

Webster, P. (2002). Computer-based technology and music teaching and learning. In R. Colwell \& C. Richardson (Eds.), The new handbook of research on music teaching and learning (pp. 416-439). Oxford University Press. 